with CNTX-4975 vs the patch; however, exposure was short term, with mean $t_{1 / 2} 0.5$ h. Cis-capsaicin concentrations were insufficient for calculating PK.

Conclusion: Trans-capsaicin from CNTX-4975 injection was rapidly absorbed and eliminated. The extent of systemic exposure to trans-capsaicin was significantly higher after CNTX-4975 vs the $8 \%$ capsaicin patch.

Abstract THU0455 -Table 1.

Trans-Capsaicin PK

\begin{tabular}{|c|c|c|}
\hline Parameter & $\begin{array}{c}\text { IA CNTX-4975 } 1 \mathrm{mg} \\
\mathrm{N}=14^{\mathrm{a}}\end{array}$ & $\begin{array}{c}\text { Topical } 8 \% \text { Capsaicin } \\
\qquad \begin{array}{c}\mathrm{N}=16^{\mathrm{a}}\end{array}\end{array}$ \\
\hline$A U C_{0-t}, h \cdot p g / m L$ & $n=14$ & $n=15$ \\
\hline Mean (SD) & $3477.72(1935.045)$ & 257.57 (353.759) \\
\hline GM (\% CV) & $3035.61(55.6)$ & $85.10(137.3)$ \\
\hline Geometric LS mean & 2930.10 & 81.72 \\
\hline $\mathrm{GM}^{2}$ ratiob $(90 \% \mathrm{Cl})$ & \multicolumn{2}{|c|}{$35.85(15.00-85.71)$} \\
\hline$A U C_{0-\infty}, h \cdot p g / m L$ & $n=13$ & $n=0$ \\
\hline Mean (SD) & $3668.85(1888.667)$ & \\
\hline $\mathrm{GM}(\% \mathrm{CV})$ & $3287.05(51.5)$ & \\
\hline Geometric LS mean & 3113.42 & \\
\hline $\mathrm{GM}^{2}$ ratiob $(90 \% \mathrm{Cl})$ & \multicolumn{2}{|c|}{$\mathrm{NE}$} \\
\hline $\mathrm{C}_{\max }, \mathrm{pg} / \mathrm{mL}$ & $n=14$ & $n=16$ \\
\hline Mean (SD) & 3875.79 (2101.535) & $123.28(134.076)$ \\
\hline $\mathrm{GM}(\% \mathrm{CV})$ & $3371.88(54.2)$ & $0(108.8)$ \\
\hline Geometric LS mean & 3305.31 & $72.05^{c}$ \\
\hline GM ratiob $(90 \% \mathrm{Cl})$ & \multicolumn{2}{|c|}{$45.88(23.87-88.18)$} \\
\hline$T_{\max ,}{ }^{d} \mathrm{~h}$ & $n=14$ & $n=16$ \\
\hline Median (range) & $0.2(0-1)$ & $1.0(0-8)$ \\
\hline $\begin{array}{l}\mathrm{t}_{1 / 2}, \mathrm{~h} \\
\quad \text { Mean (SD) }\end{array}$ & $\begin{array}{c}n=13 \\
0.54(0.201)\end{array}$ & $n=0$ \\
\hline \multicolumn{3}{|c|}{ 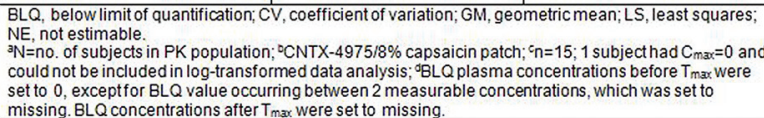 } \\
\hline
\end{tabular}

Disclosure of Interests: Randall Stevens Shareholder of: Centrexion Therapeutics Corp, Employee of: Centrexion Therapeutics Corp, Kimberly Guedes Employee of: Centrexion Therapeutics Corp, Eddie Armas: None declared, Valerie Smith Consultant for: Premier Research, Andrew Volosov Consultant for: Premier Research

DOI: 10.1136/annrheumdis-2019-eular.5941

\section{THU0456 EVALUATION OF THE USE OF ORLISTAT IN THE COMPLEX TREATMENT OF OBESITY IN PATIENTS WITH KNEE OSTEOARTHRITIS}

Ekaterina Strebkova, Ludmila Alekseeva. Nasonova research institute of rheumatology, Moscow, Russian Federation

Background: Currently in the world there is a pandemic of obesity, which leads to an increase in diseases associated with overweight. Obesity is an important factor in the development and progression of osteoarthritis $(\mathrm{OA})$. The metabolic phenotype of $\mathrm{OA}$, which is directly associated with obesity, is highlighted. Due to the growing number of patients with obesity and OA, a high level of comorbidity and the lack of effectiveness of non-drug therapy, the problem of the effectiveness and safety of the therapy of obesity is very relevant.

Objectives: To evaluate the efficacy and safety of drug therapy for obesity in patients with $O A$ of the knee.

Methods: 50 female patients (45-65 y.o.) with Kellgren-Lawrence stage IIIII KOA and obesity $\left(\mathrm{BMl}>30 \mathrm{~kg} / \mathrm{m}^{2}\right)$. Patients in Group $1(\mathrm{n}=25)$ took $120 \mathrm{mg}$ of orlistat 3 times a day in combination with a low-calorie diet and exercise for 6 months. Patients in Group $2(n=25)$ were on a low-calorie diet combined with exercise for 6 months. All patients initially received various non-steroidal anti-inflammatory drugs (NSAIDs) in tablet form. All patients were assessed for body mass, parameters of the WOMAC index, EQ-5D quality of life index, NSAID consumption, and orlistat therapy safety assessment.
Results: After 6 months of drug therapy for obesity, patients from Group 1 achieved a significant weight loss by $10.07 \%$ ( $p<0.05)$. Patients from Group 2 the use of non-medical methods of treating obesity reduced body weight by $0.84 \%$ ( $p>0.05$ ). Patients from Group 1 improved the WOMAC index: pain decreased by $52.5 \%$ ( $p<0.05$ ), stiffness by $47.98 \%$ ( $p<0.05$ ), and functional insufficiency by $51.55 \%(p<0.05)$. Patients from Group 2 also showed a decrease in the WOMAC index, but these changes were worse than in patients with greater weight loss. Patients from Group 1 showed a significant improvement in the quality of life for the EQ-5D index by $52.27 \%$ ( $p<0.05$ ). Patients from Group 2 against the background of insignificant changes in body weight, the quality of life index EQ-5D did not change. The need to take NSAIDs on the background of drug therapy for obesity and weight loss decreased by 4.6 times. On the contrary, in Group 2 of patients on the background of non-pharmacological treatment of obesity after 3 months of observation, the need for NSAIDs was maintained in $76 \%$. The need for NSAIDs in patients of Group 2 decreased 1.3 times. In general, the tolerability of orlistat in patients of Group 1 was good. Adverse reactions were observed in two patients in the form of steatorrhea. The appearance of an undesirable reaction was associated with errors in nutrition (eating food saturated with animal fats), which did not require discontinuation of the drug. After correcting the diet, no adverse reactions were noted in patients.

Conclusion: The results of our study showed a significant decrease in body weight by more than $10 \%$ in the group of patients with OA while receiving orlistat. Significant weight loss helps reduce pain intensity, improve joint function, improves the quality of life of patients with $O A$, reduces the need for NSAIDs, which can help stabilize other comorbid diseases in patients with $\mathrm{OA}$ and obesity. The study noted good safety of therapy with orlistat; no serious adverse reactions were reported. Thus, drug therapy for obesity using orlistat can be included in the management of patients with $\mathrm{OA}$ and obesity, who cannot achieve weight loss using non-drug methods.

Disclosure of Interests: : Ekaterina Strebkova: None declared, Ludmila Alekseeva Speakers bureau: Bayer, Boeringer-ingelheim, Gedeon-Richter, Servier

DOI: 10.1136/annrheumdis-2019-eular.5922

\section{\begin{tabular}{|l|l}
\hline THU0457 EVALUATION OF THE EFFECTIVENESS OF COMPLEX \\
\hline
\end{tabular} TREATMENT OF OBESITY ON THE CLINICAL MANIFESTATIONS OF KNEE OSTEOARTHRITIS AND THE DYNAMICS OF CYTOKINES, DEPENDING ON THE DEGREE OF WEIGHT LOSS}

Ekaterina Strebkova, Ludmila Alekseeva. Nasonova research institute of rheumatology, Moscow, Russian Federation

Background: Obesity is a risk factor and progression of the metabolic phenotype of osteoarthritis (OA). The decrease in body weight is important in the treatment of OA. Non-drug therapy aimed at altering the eating behavior, allows you to achieve a decrease in body weight of only $5 \%$, which does not always contribute to the achievement of the clinical effect in patients with diseases of the joints.

Objectives: Assess the effectiveness of complex treatment of obesity with the use of orlistat (intestinal lipase inhibitor) on the clinical manifestations of the knee OA and the dynamics of cytokines (CRP, IL-6, TNF- $\alpha$ ) depending on the degree of weight loss.

Methods: 50 female patients (45-65 y.o.) with Kellgren-Lawrence stage II-II $\mathrm{KOA}$ and obesity $\left(\mathrm{BMl}>30 \mathrm{~kg} / \mathrm{m}^{2}\right)$. Patients in Group $1(\mathrm{n}=25)$ took 120 $\mathrm{mg}$ of orlistat 3 times a day in combination with a low-calorie diet and exercise for 6 months. Patients in Group $2(n=25)$ were recommended non-drug therapy for obesity for 6 months. At baseline and after 6 months, the clinical parameters of the knee OA (WOMAC) were evaluated, the quality of life was assessed (EQ-5D). A laboratory study of peripheral blood was conducted at baseline and after 6 months: CRP, IL- 6 , TNF- $\alpha$.

Results: After 6 months of complex treatment of obesity with the use of orlistat, patients in Group 1 achieved a significant weight loss of $10.07 \%$ ( $p<0.05$ ). Depending on the degree of weight loss in Group 1, 15 patients lost> $10 \%$ and 10 patients lost $5-9.9 \%$ of the initial body weight. In the 2nd group, an insignificant weight loss of $0.84 \%$ ( $p>0.05$ ) was achieved, all patients in Group 2 lost less than 5\%. Depending on the degree of weight loss, it is noted that in patients with weight loss more than $5 \%$ better than WOMAC (pain, stiffness, functional state) $(p<0.05)$, EQ-5D ( $p<0.05)$ compared with less weight loss. In patients with weight loss> $10 \%$, a significant decrease in CRP level was observed $(p=0.03$ ) (Fig. 1) compared with baseline and patients with a 5-9.9\% weight loss $(p=0.03)$ and $<5 \%(p=0.02)$. Data for statistically significant changes 
from TNF- $\alpha$ and IL-6, depending on the degree of weight loss was not detected.

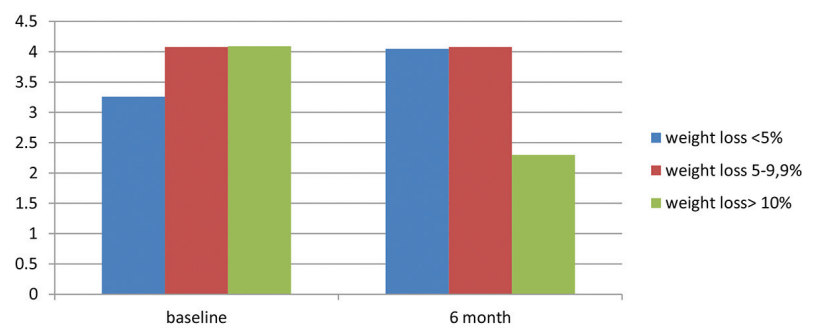

Abstract THU0457 - Figure 1. Dynamics of CRP depending on the degree of weight loss $(p<0.05)$

Conclusion: The results of the study demonstrated a significant effectiveness of the complex treatment of obesity in patients with knee OA, compared with the use of only non-pharmacological methods of weight loss. A decrease in body mass of more than $5 \%$ helps to improve the clinical manifestations of knee $\mathrm{OA}$ and the quality of life of patients. A decrease in body weight of more than $10 \%$ demonstrates a decrease in the level of CRP, which suggests an effect on meta-inflammation in OA.

Disclosure of Interests: Ekaterina Strebkova: None declared, Ludmila Alekseeva Speakers bureau: Bayer, Boeringer-ingelheim, Gedeon-Richter, Servier DOI: 10.1136/annrheumdis-2019-eular.6793

\section{THU0458 EFFICACY AND SAFETY FROM A PHASE 2B TRIAL OF SM04690, A NOVEL INTRA-ARTICULAR WNT PATHWAY INHIBITOR FOR THE TREATMENT OF OSTEOARTHRITIS OF THE KNEE}

Yusuf Yazici ${ }^{1}$, Timothy Mcalindon ${ }^{2}$, Allan Gibofsky ${ }^{3}$, Nancy Lane ${ }^{4}$

Christian Lattermann $^{5}$, Nebojsa Skrepnik ${ }^{6}$, Christopher Swearingen ${ }^{1}$,

Anita Difrancesco ${ }^{1}$, Jeyanesh Tambiah ${ }^{1}$, Marc Hochberg ${ }^{7}$. 'Samumed, LLC, San

Diego, United States of America; ${ }^{2}$ Tufts Medical Center, Boston, United States of

America; ${ }^{3}$ Weill Cornell Medical College, New York, United States of America; ${ }^{4}$ UC Davis Medical Center, Davis, United States of America; ${ }^{5}$ Brigham and Women's Hospital, Boston, United States of America; ${ }^{6}$ Tucson Orthopedic Institute, Tucson, United States of America; ${ }^{7}$ University of Maryland School of Medicine, Baltimore, United States of America

Background: A phase 2a study of SM04690, a small-molecule, intra-articular (IA) Wnt pathway inhibitor reduced knee pain and improved physical function and medial joint space width (mJSW) at 52 weeks in subgroups of subjects with unilateral symptomatic knee osteoarthritis (OA) compared to placebo $(\mathrm{PBO}){ }^{1}$

Objectives: A 24-week phase $2 \mathrm{~b}$ study was conducted to refine patientreported outcome (PRO) measures, target population, medication dose, and to evaluate safety. PRO results for Weeks 12 and 24 are presented here.

Methods: Study subject inclusion criteria required ACR-defined knee OA, Kellgren-Lawrence (KL) grades 2-3, and Pain Numeric Rating Scale (NRS) $\geq 4$ and $\leq 8$ in the target knee and $<4$ in the contralateral knee. A single IA injection of $2 \mathrm{~mL} S M 04690(0.03,0.07,0.15$, or $0.23 \mathrm{mg})$, vehicle $\mathrm{PBO}$, or sham (dry needle only) was given in the target knee at baseline. PRO endpoints included change from baseline in weekly average of daily pain in the target knee by NRS diary (NRS) [0-10], Western Ontario and McMaster Universities Osteoarthritis Index (WOMAC) Pain [0-100], WOMAC Physical Function [0-100], and Patient Global Assessment (PtGA) [0-100]. Differences between active treatment groups and vehicle PBO were analyzed with baseline-adjusted analysis of covariance (ANCOVA).

Results: 695 subjects (mean age 59.0 [ \pm 8.5$]$ years, BMI 29.0 [ \pm 4.0$]$ kg/ $\mathrm{m}^{2}$, female $58.4 \%$, KL3 57.3\%) were enrolled and dosed; 635 subjects (91.4\%) completed the study. No meaningful differences in the incidence of adverse events were observed between treatment and control groups. In the Full Analysis Set, significant improvements from baseline compared to vehicle PBO were observed in pain NRS for $0.07 \mathrm{mg}$ (Week 12 $[P=0.001]$, Week $24[P=0.031]$ ) and $0.23 \mathrm{mg}$ (Week $12[P=0.012]$, Week $24[P=0.022])$ SM04690 dose groups (Figure). Similar improvements were observed in WOMAC Pain for $0.07 \mathrm{mg}$ (Week $12[P=0.04]$ ) and $0.23 \mathrm{mg}$ (Week $12[P=0.003]$, Week $24[P=0.031]$ ) dose groups. For WOMAC Physical Function, improvements were observed for $0.07 \mathrm{mg}$ (Week 12 $[p=0.021])$ and $0.23 \mathrm{mg}$ (Week $12[p=0.006]$, Week $24[P=0.017])$ dose groups. PtGA improvements were observed for $0.07 \mathrm{mg}$ (Week 12
$[P=0.031])$ and $0.23 \mathrm{mg}$ (Week $12[P=0.010]$, Week $24[P=0.033])$ dose groups.

Conclusion: SM04690, in development as a potential disease-modifying OA drug, showed in this phase $2 b$ study statistically significant improvements from baseline in both the $0.07 \mathrm{mg}$ and $0.23 \mathrm{mg}$ dose groups compared to vehicle $\mathrm{PBO}$ for Pain NRS, WOMAC Pain, WOMAC Physical Function, and PtGA. These data support the continued development of SM04690 as a treatment for knee OA. Phase 3 studies are being planned.

\section{REFERENCE:}

[1] Yazici Y, et al. Arthritis Rheumatol. 2017; 69 (suppl 10).
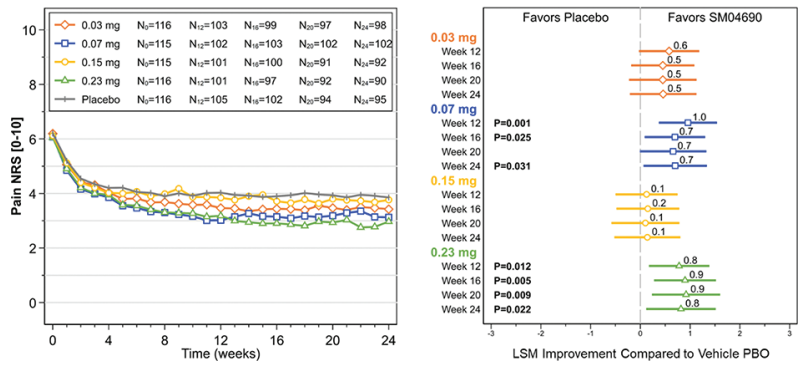

Figure. Actual observations over time and ladder plots depicting least squares mean (LSM) improvement of Pain NRS $( \pm 95 \% \mathrm{Cl}$ ) in SM04690 compared to vehicle PBO, adjusted for baseline.

Disclosure of Interests: Yusuf Yazici Shareholder of: Samumed, LLC Consultant for: Celgene Corporation, BMS, Genentech, Sanofi, Employee of: Samumed, LLC, Timothy McAlindon Grant/research support from: Samumed, LLC, Consultant for: Samumed, LLC, Astellas, Flexion, Pfizer, Regeneron,

Seikugaku, Allan Gibofsky Shareholder of: AbbVie, Amgen, Johnson\&Johnson, Regeneron, Consultant for: AbbVie, Pfizer, Horizon, Celgene, Novartis/Sandoz, Samumed, LLC, Merck, Flexion, Lilly, Speakers bureau: AbbVie, Celgene, Pfizer, Flexion, Lilly, Merck, Nancy Lane Consultant for: Samumed, LLC, Christian Lattermann Shareholder of: Cocoon, Consultant for: Samumed, LLC, Vericel, Cariheal, Joint Restoration Foundation, Nebojsa Skrepnik Grant/research support from: Samumed, LLC, Consultant for: Orthofix, Sanofi, Regeneron, Christopher Swearingen Shareholder of: Samumed, LLC, Employee of: Samumed, LLC, Anita DiFrancesco Shareholder of: Samumed, LLC, Employee of: Samumed, LLC, Jeyanesh Tambiah Shareholder of: Samumed, LLC, Employee of: Samumed, LLC, Marc Hochberg Shareholder of: BriOri Biotech, Theralogix LLC., Consultant for: Bristol Myers Squibb, Eli Lilly, EMD Serono, Novartis Pharma AG, Pfizer Inc., Samumed LLC, Symic Bio Inc., Theralogix LLC, TissueGene Inc. TLC Biopharmaceuticals, Inc., Zynerba, Galapagos, IQVIA, Hoffman LaRoche.

DOI: 10.1136/annrheumdis-2019-eular.5045

\section{THU0459 PREDICTORS ASSOCIATED WITH RAPID PROGRESSION OF KNEE OSTEOARTHRITIS}

Elena Taskina ${ }^{1}$, Ludmila Alekseeva ${ }^{1}$, Natalia Kashevarova ${ }^{1}$, Sergey Anikin ${ }^{1}$, Evgenia Sharapova ${ }^{1}$, Ekaterina Strebkova ${ }^{1}$, Lena Zonova ${ }^{2}$, Tatiana Raskina ${ }^{3}$, Elvira Otteva ${ }^{4}$, Irina Vinogradova ${ }^{5}$, Aleksandr Lila ${ }^{1}{ }^{1}$ V. A. Nasonova Research Institute of Rheumatology, Moscow, Russian Federation; ${ }^{2}$ FSBEI HE Novosibirsk State Medical University, Novosibirsk, Russian Federation; ${ }^{3}$ SBEI HE KemSMU $\mathrm{MOH}$, Kemerovo, Russian Federation; ${ }^{4}$ Regional SBHI CDC MOH Khabarovsky kray, Khabarovsk, Russian Federation; ${ }^{5}$ SHI Ulyanovsk regional affiliated hospital, Ulyanovsk, Russian Federation

Objectives: To identify knee OA rapid progression factors in a multicenter prospective study

Methods: 185 female patients from 5 RF constituent territories aged 4075 with confirmed Kellgren-Lawrence score grade I-III knee OA were included into prospective study after signing the informed consent form Mean age was $59,2 \pm 7,4$ years (42-75), mean BMl-27,7 $\pm 4,4 \mathrm{~kg} / \mathrm{m}^{2}$, mean disease duration-12 $\pm 8,1$ years. Individual patient's medical record included relevant anthropometric data, records from case history and clinical examination, VAS articular pain assessment, WOMAC scores, comorbidities. Instrumental diagnostic methods included plain radiography of knee joints, DEXA of the lumbar spine and femoral neck, MRI examination of knee joints. Stage II knee OA was established in 135 (73\%) out of 185 patients, stage III - in 50 (27\%). 